by W.S. Fyfe

\title{
The International Geosphere/Biosphere Programme and global change: An anthropocentric or an ecocentric future? A personal view
}

\begin{abstract}
Rapid and life-threatening changes in the global life-support system are accelerating and forcing the human species to decide between Nature itself or a totally anthropocentric view of the management of planet Earth. We have a very short time to decide this issue of ultimate values, but the results from an International Geosphere/Biosphere Programme are essential for rational choice. For security, we must protect and vastly expand the planet's biological reserves on land and at sea.
\end{abstract}

\section{Introduction}

We often hear that we live at a unique, critical time in the history of the human species. However, we are frequently suspicious of such statements, for our ancestors surely made similar statements - but this period of our history is unique. First, we possess a nuclear arsenal that, if used, could destroy, in a few days, our species and take many others with us. In addition, we have other technologies that could do the same. Second. because of a complex array of, for example. energy. medical. chemical, agricultural, and transport technologies. we have never before increased in population with such success. The last time we doubled our population took 37 years, compared to the 1.500 years it took after the birth of Christ. We know that what is happening now cannot continue.

The roots of the initiative for global change go very deep, and they were well summarized by Thomas Malone in 1984 (see Malone. 1985 ) during the general assembly of the International Council of Scientific Unions (ICSU) in Ottawa, Ontario, Canada. Charles Lyell said in 1872 (p. 451 ): "In reference to the extinction of species it is important to bear in mind, that when any region is stocked with as great a variety of animals and plants as its productive powers will enable it to support. the addition of any new species to the permanent numerical increase of one previously established, must always be attended either by the local extermination or the numerical decrease of some other species." Perhaps no better example could be given than that of what is now happening in the Amazon basin of South America as it is invaded by man. And this case may serve to show that a "local" event may have global consequences.

Then followed Vernadsky in 1929 (see Vernadsky. 1986), who had a clear appreciation of the fact that the biosphere was a critical part of the surface systems of our planet. After such champions, the social scientists perhaps led the game. I think of people like Aldous Huxley, who said in 1948 (see Bedford. 1987. p. 82):

Industrialism is the systematic exploitation of wasting assets. In all too many cases, the thing we call progress is merely an acceleration in the rate of that exploitation. Such prosperity as we have known up to the present is the consequence of rapidly spending the planet's irreplaceable capital.

Sooner or later mankind will be forced by the pressure of circumstances to take concerted action against its own destructive and suicidal tendencies. The longer such action is postponed, the worse it will be for all concerned... . Overpopulation and erosion constitute a Martian invasion of the planet.

Treat Nature aggressively, with greed and violence and incomprehension: wounded Nature will turn and destroy you.... if, presumptuously imagining that we can "conquer" Nature, we continue to live on our planet like a swarm of destructive parasites - we condemn ourselves and our children to misery and deepening squalor and the despair that finds expression in the frenzies of collective violence.

In 1982 at the assembly of the ICSU in Cambridge. England. George Garland, geophysicist from Toronto. Ontario, Canada, suggested that it was time to look carefully at the influences of biological processes on our planet. Also, Herbert Friedman, who made major contributions to international science through the International Geophysical Year in 1957-58, suggested that it was time for a bold, holistic approach to the science of Earth. And in 1986 at the general assembly of the ICSU in Switzerland, the International Geosphere/ Biosphere Programme (IGBP) was launched officially. Much of its philosophy and approach was taken from the report of the working group of the USA, which was chaired by Jack Eddy (see NRC, 1986). The focus of IGBP was clear: to understand the interactions in the global environment that involve the biosphere. Thus, it was seen to be a highly focused effort to fill the critical gaps in our knowledge of the surface interfaces of the planet or the system:

$$
\text { Sun } \rightarrow \text { living cell } \leftarrow \text { Earth }
$$

I always remember the wonderful words of Roger Revelle of the Scripps Institution of Oceanography at one of the early USA planning meetings. He said that the IGBP was urgent (for obvious reasons) and hard because it required observations and communication across all the geologic and biologic disciplines on a scale never seen before. The normal university research structures and programs were poorly prepared for a research program of this scope. However, the IGBP was clearly possible in the 1980 s. For the first time in the history of the observation of natural systems, almost all the tools were available: satellites, submersibles, mass spectrometers, electron microscopes, and supercolliders, for example. The dynamics of the largest and smallest pieces of the puzzle can be described and the data managed by using the new and increasing power of computers. 
In introducing the IGBP to the world, Sir John Kendrew (1988, p. 3), the president of ICSU, stated:

The IGBP will certainly be the most ambitious, the most wide-ranging, and in its impacts on our understanding of the future possibilities for mankind the most important project that ICSU has ever undertaken. Its purpose is to study the progressive changes in the environment of the human species on this Earth, past and future: to identify their causes, natural or man-made: and to make informed predictions of the long-term future and thus of the dangers to our well being and even to our survival; and to investigate ways of minimizing those dangers that may be open to human intervention. From the point of view of fundamental science it is the extended study of the dynamics of the whole Earth system-its geology, its occans, its atmosphere and its climate, and the thin green layer on its surface that we call the biosphere; a scientific enquiry offering immense intellectual challenges and rewards. So the programme will be scientifically exciting as well as immensely significant in charting the future of our species. It will necessarily continue for many years and will require the collection and analysis of huge amounts of data of all kinds using the most sophisticated techniques and the most powerful computers. It will be a major endeavor of the scientific community in every country of the world

Part of the IGBP, a so-called underlying theme, was to understand human perturbations on the global system and to improve our ability to predict the state of the life-support system in the coming decades and centuries.

Words are often very important! By itself, the program named "IGBP" is focused, but when we use the words "global change," the concept is vast. In fact, global change has become what we might almost call a societal-scientific movement. Differences between various approaches and priorities are seen clearly in the programs that are expressed by the growing national efforts and national reports, and this is as it should be-and must be. We have truly global needs (for example, the study of the dynamics of the ocean, atmosphere, land surface, and biology), and we have equally valid local priorities, where local environmental changes influence local societies. However, I am always reminded of the words of Lyell (1872), who recognized that a special local advantage of a species can lead to a much longer term global perturbation. One need think only of the field of epidemiology (for example. AIDS) in order to appreciate Lyell's thoughts. And as the new work in genetic manipulation moves forward, we may see vast changes in the biosphere and we may face equally vast surprises.

\section{The system}

We surely live on the most remarkable object in the solar system (Mungall and McLaren, 1990). The geologic record shows that we have been almost covered by liquid water for 4 billion years, nearly 90 percent of the planet's history. In fact, the development of the geologic record may have started because of the hydrosphere and its moderating influence. The record also shows that, despite fluctuations in the Earth and Sun, we have never boiled dry or totally frozen. Planet Earth has a truly remarkable themostat, and today we know that the biosphere plays a key role in the functioning of the thermostat.

Certainly, we must begin to understand the interactions, on all time scales, of the great nuclear power sources that drive the surface processes of the Earth. We must begin to understand their fluctuation on many time scales, as well as the mechanisms that link such changes to changes in the biomass. We do not really understand how small changes in solar input can be amplified through the atmosphere. At the other end of the power sources, we do not understand how changes in energy from the interior of Earth, expressed by such processes as volcanism and the water-cooling fluxes associated with such phenomena, influence the biosphere. We do know that these irregular processes can perturb the dust loading and chemistry of the atmosphere, as well as change the nutrient fluxes into the oceans (Groves, 1988; Fyfe, 1988). The development of the program on natural hazard reductions emphasizes the need to understand better (and prepare for) the short-term fluctuations that are driven from the Earth's interior or atmosphere.

We have also become aware of our lack of knowledge of the biosphere, which is full of surprises about the diversity of life in the deep oceans and in the canopies of the tropical forests. Is the World watch Institute correct when it states that about 20 percent of this diversity will be destroyed in the next decade or so? We have an urgent need to know our present diversity and the unique interaction: between the pieces of the geologic and biologic systems.

\section{The rise of Homo sapiens}

I think there is little doubt that the new scientific programs are with us because of the phenomenal increase in the human population. When Christ was born, the population was about 200 million. It then took about 1,500 years to double to 400 million. In 1900, the population was about 1.5 billion, and now it is over 5 billion and rising about 90 million per year, the last time doubling in 37 years! The population may well reach 10 billion toward the middle of next century, but the major increases will be in specific regions (for example Nigeria may go from 105 to 300 million by 2025; Egypt, 51 to 100 million; India, 819 to 1,500 million). If this happens, the patterns of land use and industrialization must change dramatically and very fast.

\section{The shock of the record}

As the population of Homo sapiens has changed. so has our environment. We have been shocked by the record of gases, such as carbon dioxide, methane, and halogen organics, in the atmosphere. We have been shocked by the record of soil erosion and deforestation. In 1987, 8 million hectares of the Amazon was cleared; in 1989.6.4 million hectares burned in Canada.

Studies of ice cores. ocean sediments, and terrestrial vegetation have shown us that the climate and atmosphere are tightly coupled and that major temperature changes can occur in periods of a century, or even less. Models of the future trends of temperature, precipitation, and the like, even if not very reliable. give cause for alarm. As we obtain better data over the next decades and produce better models, we will have even greater surprises. I am reminded of a speech by Mrs. Dahl, the Swedish Minister of Energy and Environment, who said that we cannot wait for scientists to be certainwe must prepare now!

Slowly, we see the growth of a new approach to the economics of development. In no area is this more apparent (and confused!) than in planning our global energy technologies for the future. The world, and particularly countries like the People's Republic of China and India, have great coal resources. enough for centuries. The developing world urgently needs more energy. While the New World, and particularly North America. must conserve (why do we use twice the energy per person compared to Europe?), the Old World and Third World need more energy. What will be the costs of using more fossil carbon if sea level rises a meter and if the cornlands and wheatlands of North America become much drier? What is the cost 
of hydroelectric power and its resulting loss of arable land at the time of a growing global food crisis?

\section{Diversity}

At present, we are alarmed by the reduction of biological diversity on this planet. As the opening quotation from Lyell states so clearly, one species cannot possibly expand without the accompanying reduction of others. And, for all our cleverness, the destruction of a species is irreversible. The French essayist Montaigne wrote 400 years ago that "the universal quality is diversity." The stability of our system also seems to require diversity. We must face squarely the reality that, if the human population continues to expand, an inevitable and massive loss of diversity will result. From this loss of diversity will come the potential for loss both in the stability of our own lifesupport system and in its ability to survive the changes caused by the fundamental systems of the planet.

In this context, the Bruntland Report (The World Commission on Environment and Development, 1987) has its fatal flaws. As given in the final statements, "General Principles, Rights, and Responsibilities, Number One, All human beings have the fundamental right to an environment adequate for their health and well-being." This is clearly an anthropocentric view of our planet. Why should we have this fundamental right if we do not use our knowledge with wisdom? As David Pimentel of Cornell (1987, p. 692) stated:

"World resources and technology can support an abundance of humans, e.g., 10-15 billion humans living at or near poverty, or support approximately one billion humans with a relatively high standard of living."

\section{Conclusion}

We are entering a new period for the science of our planet. We must understand how our planet maintains its surface systems, which support all life. We can do this, as we have the tools for the necessary observations. Our programs related to global change must have the breadth and the dynamics to respond to the inevitable surprises that will come. I have great hope for the future because of the rapid changes that are occurring in social attitudes in many parts of the world, a changeover to what I would term an "ecocentric" view of the sustainable development of Earth.

We have a choice, a difficult, terrible choice. Bill McKibben eloquently described this choice in the New Yorker in September 1989 (p. 47-105; see also McKibben, 1989): Do we want to preserve Nature? It is now almost gone! Or do we want a totally anthropo-planned, anthropo-managed planet? Given the inevitable expansion of modern biotechnologies, it has never been so important for us to protect and expand the biological reserves in all of our planet's major regimes. Perhaps the most important features of life come from the unexpected. An anthropo-managed planet would be uniform, safe, predictable, and dead.

I remember a lecture at the University of California at Berkeley in the USA, long ago, by the great scientist and philosopher Michael Polanyi of Manchester, England. He said that if we knew exactly when the tulips would bloom, we would not bother to plant tulips.

\section{References}

Bedford, S., 1987, Aldous Huxley, a biography: London, Paladin Grafton Books, v. 2, 378 p.

Fyfe, W.S., 1988, Deep earth fluxes and the biosphere: Bulletin of the Geological Institutions of the University of Uppsala, N.S. 14, p. 13-20.

Grove, J.M., 1988, The little ice age: London, Methuen, 498 p.

Kendrew, John, 1988, Foreword, in The International Geosphere-Biosphere Programme: A study of global change (IGBP): Stockholm, IGBP Global Change Report 4, 1988, p. 3-5.

Lyell, Charles, 1872, Principles of geology (11th edition): London, John Murray, v. 2, 652 p.

McKibben, Bill, 1989. The end of Nature: New York, Random House, $226 \mathrm{p}$.

Malone, T.F., 1985, Preface, in Malone, T.F., and Roederer, J.G., eds., Global change: Cambridge, UK. Cambridge University Press, p. xi-xxi

Mungall, C., and McLaren, D.J., eds., 1990, Planet under stress: The challenge of global change: Toronto, Oxford University Press and the Royal Society of Canada, 344 p.

NRC (National Research Council), 1986, Global change in the geospherebiosphere: Initial priorities for an IGBP: Washington, D.C., National Academy Press, $91 \mathrm{p}$.

Pimentel, David, 1987, Technology and natural resources, in McLaren, D.J., and Skinner, B.J., eds., Resources and world development, Dahlem workshop reports: New York, John Wiley, p. 679-696.

The World Commission on Environment and Development, 1987, Our common future: Oxford, Oxford University Press, 383 p.

Vernadsky, V.I., 1986, The biosphere: Oxford, Synergetic Press, Inc., 82 p. [English language edition published in 1986 based on the 1929 edition in French].

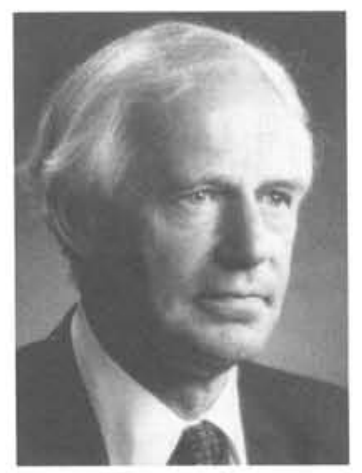

W.S. Fyfe was born on a farm in New Zealand. He studied geology and chemistry at Otago University. He has taught in New Zealand and at the University of California at Berkeley and Los Angeles, Manchester University (UK), Imperial College (London) and the University of Western Ontario in Canada, where hs is presently Dean of Science. Fyfe is a Fellow of the Royal Scotity of London and Canada. He recently received the Authur Holmes Medal of the European Union of Geosciences. 